\title{
Cidadania e saúde mental no Brasil: contribuição ao debate
}

\author{
Citizenship and mental health in Brazil: \\ a contribution to the debate
}

Soraya Maria de Medeiros 1

Jacileide Guimarães 2

\footnotetext{
1 Departamento de Enfermagem da Universidade Federal do Rio Grande do Norte. Rua Joaquim Fabrício 260/602, Edifício Presidente Kennedy. 59012-340 Natal RN. sorayamaria@uol.com.br 2 Programa de Pós-Graduação em Enfermagem Psiquiátrica e Saúde Mental da Escola de Enfermagem de Ribeirão Preto.
}

Abstract The Brazilian debate around the exercise of the citizenship, in special, the scope of the sector health, recrudesces in the 1964 after-dictatorship, being distinguished the end of the decade of 70 as bubbling of questionings and organized movements. But valley to stand out the origin and destination of the citizenship that in Brazil was satisfied and is still satisfied, predominantly, as regulated, grantee, or either, a "settlement of accounts" granted in detriment of the real correspondence of the right of the diverse segment of the society, especially, of less the most favored. In the Brazilian mental health, already marked for critical elementary of the to overcrowd room and the inefficiency of the hospices, it is given for 1978 rollback the incipient organization of a new to look at on the Brazilian psychiatric assistance, where from now on, it is gone to foment in Brazil, the critical one not only to the structural situation of the lunatic asylum, but also and mainly to the authoritarian speech of erudition/power of psychiatry. Under this point of view the citizenship starts to be fulcrum of the new Brazilian psychiatric speech that, from 1990 with the Declaration of Caracas, only starts to have greater to be able of confrontation of the traditional assistance.

Key words Citizenship, Health, Mental health, Brazil
Resumo $O$ debate brasileiro em torno do exercício da cidadania, em especial, no âmbito do setor saúde, recrudesce no pós-ditadura de 1964, destacando-se o final da década de 1970 com efervescência de questionamentos e movimentos organizados. Mas vale ressaltar a origem e destino da cidadania que no Brasil conformou-se e conforma-se ainda, predominantemente, como regulada, outorgada, ou seja, um "acerto de contas" concedido em detrimento da correspondência real dos direitos dos diversos segmentos da sociedade, especialmente, dos menos favorecidos. Na saúde mental brasileira, já marcada pela crítica elementar da superlotação e ineficiência dos hospícios, dá-se por volta de 1978 a organização incipiente de um novo olhar sobre a assistência psiquiátrica brasileira, fomentando-se a partir de então no Brasil a crítica não apenas à situação estrutural do manicômio, mas também e principalmente ao discurso autoritário do saber/prática da psiquiatria. Sob essa ótica a cidadania passa a ser fulcro do novo discurso psiquiátrico brasileiro, que, a partir de $1990 \mathrm{com}$ a Declaração de Caracas, passa a ter maior poder de enfrentamento sobre a assistência tradicional. Palavras-chave Cidadania, Saúde, Saúde mental, Brasil 


\section{Introdução}

Segundo Dallari apud Scherer (1987), a origem do conceito de cidadão se deu durante a Revolução Francesa como uma demonstração de igualdade de todos. Não havia mais nobres e plebeus, livres e escravos: havia apenas cidadãos e o cidadão é dependente do Estado, que estabelece regras para aquisição da cidadania, diz quais são os seus direitos e as condições para gozá-los, fixando também as hipóteses de sua perda. Nessa ótica de delimitações jurídicas para a expressão e condução da cidadania levada a cabo pelo Estado, a cidadania é uma invenção do Estado por meio da qual o cidadão passa a ser moldado e controlado. Assim pode-se observar que não vem sendo raro que os direitos fundamentais da pessoa sejam negados ou restringidos por leis que tratem dos direitos da cidadania.

Para Costa (1988), a questão da cidadania vem sendo colocada nas sociedades modernas com o advento do capitalismo. A autora resgata o sentido etimológico da palavra derivada da noção de cidadão. Covre (1991) atribui a origem da cidadania à polis grega, que era composta por cidadãos livres, com participação política contínua numa democracia direta onde esses cidadãos atuavam numa esfera privada (particular) e numa esfera pública (coletividade). Arendt (1999) aborda a origem da cidadania da polis grega ao liberalismo. No presente trabalho nos detemos a uma abordagem da cidadania no modo de produção capitalista. Com a constituição da sociedade burguesa, há uma passagem do centro da vida econômica das atividades agrícolas no campo para as atividades industriais nas cidades.

Na época moderna, essa mudança de cenário campo/cidade passa a determinar a emergência de novas relações sociais, nas quais a cidade e a indústria passam a ditar as condições de produção agrícola bem como as próprias condições de vida no campo e em geral.

Costa (1988) diz ainda que é dentro desta compreensão que se processa a passagem da cidadania dos burgueses medievais à cidadania nacional, cuja história é a da formação e unificação do estado moderno e o conseqüente desenvolvimento e generalização da economia mercantil. São essas determinações que, para esta autora, constituem o sentido político da cidadania.

Marshall (1967) analisa a evolução histórica da noção de cidadania na Inglaterra centrando-se em três elementos: 1) direitos civis em primeiro lugar: o elemento civil que é a liberda- de individual de escolha de pensamento, religião, etc., e o direito de defendê-los; 2) direitos políticos: o componente político que se refere ao direito à participação como eleitor ou autoridade política de uma dada organização social; 3) direitos sociais, que só passaram a fazer parte do conceito de cidadania em meados do século 20 : o elemento social que se refere ao direito de viver como ser coletivo, de acordo com os padrões prevalecentes na sociedade. Para Covre (1991), Marshall estabelece o aparecimento dos direitos civis, políticos e sociais, correspondendo, cada um deles respectivamente, às etapas do capitalismo: mercantilismo, liberalismo e monopolismo. A autora faz uma ressalva, ao dizer que, nesses diferentes momentos, o direito de reivindicar tais direitos processou-se bem mais do que o atendimento dos mesmos.

Segundo Scherer (1987), a importância dessa interpretação de Marshall está, particularmente, no fato de que o autor vincula o desenvolvimento do conceito de cidadania ao desenvolvimento simultâneo do capitalismo, pontuando o caráter de contradições e confrontos entre esse modo de produção como sistema suscitador de desigualdades sociais e, paradoxalmente, fomentador da luta contra a desigualdade inerente à luta pela cidadania.

Marshall (1967) verifica que embora a cidadania pouco tivesse feito para diminuir as desigualdades sociais no final do século 19 , não se pode negar que ela abriu caminho para a criação de políticas mais igualitárias no século 20.

Covre (1991) retoma Marshall, mas adverte que essa divisão - direitos civis, políticos e sociais - serve apenas para fins de análise. Isso porque, para que os direitos referidos sejam efetivamente atendidos, eles devem existir interligados, uma vez que o atendimento real dos direitos civis e/ou sociais depende do cumprimento dos direitos políticos e vice-versa.

$\mathrm{O}$ presente texto consiste em um ensaio acerca da cidadania no âmbito da saúde no Brasil, cujo objetivo é contribuir para o debate das políticas e práticas da saúde mental brasileira.

\section{Cidadania no Brasil}

Estudos brasileiros sobre cidadania afirmam que o exercício dos direitos civis, políticos e sociais constituem, ainda hoje, privilégio dos países de democracias modernas ocidentais sob a experiência do Welfare State. Essa tese, no entanto, é refutada frente às experiências dos últi- 
mos decênios quando se pode aferir o exacerbamento das desigualdades sociais em países centrais como a Grã-Bretanha, Alemanha e os Estados Unidos (Jaguaribe apud Scherer, 1987).

Aqui inserimos o nosso questionamento: fazendo parte do grupo de países periféricos, como o Brasil se coloca hoje em relação à conquista e ao exercício da cidadania?

A luta pela cidadania no Brasil adquire visibilidade social a partir do Estado autoritário de Vargas (1930-1945). Nesse período, paralelamente à criação das condições para o desenvolvimento do Estado burguês, foram "conquistadas" - diga-se melhor, outorgadas - as leis sociais dos trabalhadores, estabelecendo-se assim os limites e condições de funcionamento da força de trabalho. Sem dúvida, essa mesma legislação estabelece as condições e os limites sociais e políticos para a atuação dos assalariados (Costa, 1988). Assim, na conjuntura do Estado autoritário varguista, que se apresentava como preocupado em atender aos direitos sociais dos trabalhadores, tinha-se como estratagema a tutela que controlava e enfraquecia as classes trabalhadoras ao dividi-las no seu interior. Porque, se por um lado, as condições do processo produtivo em desenvolvimento refletiam as desigualdades sociais, por outro lado, a legislação trabalhista, sindical e previdenciária promulgada naquele momento - de inspiração fascista - tinha como modelo o corporativismo e o caráter perseguidor e supressor dos conflitos sociais. Desse modo, a cidadania que começava a se configurar no Brasil já era marcadamente desigual. Haja vista, por exemplo, a questão dos serviços previdenciários, que naquela época foram estendidos às categorias dos portuários, ferroviários e militares, porque essas categorias tinham força política, frente aos interesses econômicos daquele momento no país. Porém, a estratificação dessas categorias de trabalhadores terminou por produzir, no seu próprio interior, a desigualdade no acesso aos direitos desses trabalhadores.

Para Scherer (1987), na história brasileira, a existência de pressão, por parte dos trabalhadores, como reivindicação dos direitos de cidadania, é anterior a 1930, pois o que aconteceu durante a política populista dos anos 30 não pode ser entendido sem pressupor a força popular dos anos anteriores. Mas considera que a trajetória de luta pela conquista desse status está marcada pela antecipação do Estado em agir de forma tutelar, incorporando gradualmente as reivindicações das classes populares, como su- gere Maria Célia Paoli. Essa luta se dá em dois sentidos: primeiro, não permitindo que o movimento operário se organizasse de forma autônoma; e, segundo, reduzindo as questões "não relevantes", isto é, fora do projeto de dominação (Paoli, 1983).

Para se entender melhor a política econômico-social desse período, vale registrar o conceito de cidadania regulada, de Wanderley Guilherme dos Santos, também resgatado por Amélia Cohn (1996) no primeiro capítulo do livro Saúde no Brasil: políticas e organização de serviços. Trata-se do conceito de cidadania cujas raizes encontram-se, não em um código de valores, mas num sistema de estratificação ocupacional, e que, ademais, tal sistema de estratificação ocupacional é definido como norma legal (Santos, 1979).

Conforme essa lógica, são considerados cidadãos os trabalhadores que se encontram engajados na produção e cujas ocupações sejam reconhecidas e definidas por lei. Isso promove o aparecimento de uma cidadania hierarquizada, uma vez que a cidadania está embutida na profissão, e os direitos dos cidadãos restringem-se aos direitos do lugar que ocupa no processo produtivo, tal como reconhecido por lei (Santos, 1979).

Assim, aqueles trabalhadores cuja ocupação a lei "desconhece" são considerados pré-cidadãos pelo Estado, que passa a ter a função de discriminar os cidadãos em primeira, segunda e até terceira classe. Trata-se da construção de uma cidadania hierarquizada por segmentos sociais nos países de Terceiro Mundo (Sposati et al., 1995).

No período de 1945 a 1964, chamado de período de redemocratização pós-ditadura varguista, teve-se a legalização, durante um curto espaço de tempo, de um partido operário (o então Partido Comunista do Brasil); as liberdades políticas foram restauradas, incluindo o direito de voto, embora, com ressalva para o veto ao voto dos analfabetos. Para Santos (1979), no período de 1945 até 1964, o Estado Brasileiro pautou-se pelo princípio de cidadania regulada e da submissão de justiça ao princípio de maximização de eficiência do mercado.

Com o Golpe Militar de 1964, que, em si, já significava uma violação à Constituição de 1946 - elaborada através de uma Assembléia Nacional Constituinte -, o Governo, na figura do presidente da República, passa a legislar por Atos Institucionais e Leis Complementares. Através do Ato Institucional no 05 (AI-5), de 13/12/68, o presidente da República decretou o recesso do Congresso Nacional, das Assem- 
bléias Legislativas e das Câmaras de Vereadores, ficando assim o Executivo com poderes para legislar e exercer as atribuições dessas outras instâncias. Dava poderes ao presidente da República para suspender os direitos políticos de qualquer cidadão pelo prazo de 10 anos e cassar mandatos eletivos federais, estaduais e municipais. Dessa forma, os partidos políticos ficaram imobilizados e, junto com eles, o próprio Legislativo, assim como as possibilidades de representação dos direitos civis (democracia representativa) e os movimentos sociais, em suas várias instâncias, foram calados através das prisões, extermínios, torturas e exílios de suas lideranças e desmantelamento sistemático de suas estruturas organizacionais. O Estado promoveu também alterações constitucionais na Lei de Imprensa, foram criadas a Lei Antigreve e a Lei de Segurança Nacional, modificou-se o Estatuto do Estrangeiro. O Regime de Estabilidade no Emprego sai de cena e entra o Fundo de Garantia por Tempo de Serviço (FGTS). Os salários passaram a ser reajustados com base em índices inferiores à inflação.

O regime militar caracterizou-se pelo alijamento da sociedade civil, que passa a ser considerada perigosa aos interesses do bloco no poder e, por isso, tutelada e vigiada pelo Estado. Assim, a ditadura suprime drasticamente a escassa cidadania conquistada pela classe trabalhadora antes de 1964 (Scherer, 1987).

No período do chamado "milagre brasileiro" - conseguido graças à miséria das classes trabalhadoras -, além do caráter repressivo do Estado, viabilizaram-se outros mecanismos para alcançar-se o desenvolvimento. Esses mecanismos aumentaram a exploração da força de trabalho, tais como a extensão da jornada de trabalho, a institucionalização das horas extras, a intensificação do ritmo de trabalho, entre outras medidas, visando ao aumento da produtividade. É sob o signo da exploração que o padrão de vida das classes trabalhadoras se deteriora e a questão social é tratada pelos aparelhos repressivos (Scherer, 1987).

Por outro lado, cria-se um vasto aparelho institucional de políticas sociais sob a égide da ideologia do desenvolvimento e segurança nacional. Apesar de todo um discurso de uma política de benefícios sociais - constatava-se o aumento das tensões sociais nessa conjuntura -, emergem no cenário político brasileiro os movimentos de bairros e o reaparecimento - com intervenção mais consistente e forte organização - dos operários urbanos e dos trabalhado- res rurais. A emergência de uns e o fortalecimento de outros movimentos se dão a partir de 1976/77 e apontam na perspectiva de ampliação da cidadania: a luta pelo direito da posse de terra, pela igualdade entre homem/mulher, contra a discriminação racial, por direito à creche, pela terra e reservas indígenas, pelo direito de se exprimir social e politicamente, por uma sociedade sem manicômio e por participação nas decisões do poder, entre outras questões (Scherer, 1987; Amarante, 1998).

Nesse âmbito, de fomento do questionamento e da participação social, vale ressaltar a abordagem da cidadania nas suas contradições internas, para se analisar em que conjuntura política ela atua, para que sentido aponta e a quem serve.

Segundo Fleury (1989), a cidadania constitui o fundamento de legitimidade do poder político que pode traduzir-se em um efeito de mascaramento responsável pela reprodução social de forma normativa e acrítica. Mas, por outro lado, seu conhecimento, contraditoriamente, foi imprescindivel para a constituição, organização e luta das classes dominadas.

Essa organização e luta das classes dominadas que vinha sendo reconstruída no pós-64, continua com a Nova República, uma vez que nesta não há espaço para o exercício pleno da cidadania. A Nova República convivia com as instituições herdadas do Estado Novo e da Ditadura Militar, fazendo uso da legislação antigreve, da proibição da sindicalização dos funcionários públicos e de um vasto arsenal antidemocrático, denominado entulho autoritário.

A década de 1980 vivencia a turbulência da instabilidade econômica marcada por várias reformas e reajustes, que mesmo assim não efetivaram um programa de estabilização. Foram:

(...) 8 planos de estabilidade econômica, $4 \mathrm{di}$ ferentes moedas, 11 indices distintos para cálculo de inflação, 5 congelamentos de preços e salários, 14 políticas salariais, 18 mudanças nas regras de câmbio, 54 mudanças nas regras de controle de preços, 21 propostas de negociação da dívida externa e 19 decretos governamentais de austeridade fiscal (Cohn, 1997).

Os anos 80 evidenciaram sinais de uma estagnação econômica, uma inflação crônica e a ingovernabilidade manifestadas em uma crise orgânica do Estado desenvolvimentista, vigente desde os anos 30 (Fiori et al., 1994).

Economicamente instável, o Brasil adentra a década de 1990 com uma política híbrida que implicava um processo de ajuste de corte neoli- 
beral, marcado por iniciativas de privatização no enfrentamento do déficit público, mas com o Estado como ator central (Cohn, 1997).

\section{Cidadania e saúde no Brasil}

Tanto do ponto de vista da literatura científica como do senso comum dos que reivindicam a cidadania, é unânime a opinião de que em qualquer sociedade que tenha proposta de/ou se autodenomine uma democracia, há dois valores básicos que têm de ser priorizados: a saúde e a educação. A priorização desses temas nas pautas de reivindicações e de plataformas de trabalho em qualquer projeto político para uma dada sociedade não está calcada apenas na defesa do bem-estar e no respeito aos direitos humanos. Estas são questões que se articulam com processos explicativos de valores e interesses, muito mais no nível do econômico e ideológico do que de referências nostálgicas aos direitos naturais apregoados pela revolução burguesa.

Covre (1991) pontua os direitos elementares de cidadania, a saber, alimentação, vestuário, educação básica, saúde, moradia, lazer e previdência social, como representantes do atendimento das necessidades básicas no processo de manutenção e reprodução da força de trabalho. E acrescenta que é a garantia desses direitos que mantém e renova a força de trabalho na sociedade.

No Brasil, nos períodos entre 1891, 1911 e 1917, surgem alguns decretos com o objetivo de regulamentar a situação sanitária das empresas industriais. Em 1919 tem-se a primeira medida de legislação social sobre acidente de trabalho que atribuía responsabilidade às empresas industriais. Em 1923 institui-se a Lei Eloy Chaves sobre a previdência social, nos anos seguintes são aprovadas as leis que vêm atender parcialmente as questões relativas à proteção do trabalho: lei de férias, código de menores, trabalho feminino, seguro doença, entre outros. Todavia, essa legislação é aplicada somente para alguns setores necessários aos interesses da economia agroexportadora.

Costa (1986) analisa as políticas sociais em articulação com as políticas de saúde no início do século e diz que as políticas de saúde pública no Brasil não se caracterizaram pela proteção da população contra surtos epidêmicos e doenças parasitárias, tampouco pela recuperação da saúde do comum dos homens, mas sim, pela articulação aos interesses dos grupos dominantes internos ou pela expansão do capitalismo em escala internacional.

No período varguista, já citado, ao mesmo tempo que os serviços previdenciários surgiam como conquista para as categorias dos portuários, ferroviários e militares - uma vez que essas categorias tinham força política visto que representavam a estrutura econômica do país naquele momento - ocorria, por outro lado, a estratificação dessas categorias de trabalhadores, promovendo uma desigualdade no interior das mesmas, gerando diferenciação no acesso aos direitos conquistados por eles.

Para Santos (1979), nesse contexto a cidadania é gerada no Brasil como cidadania regulada, por discriminar, estratificar e controlar quem trabalha e em que trabalha. Aquilo que o Estado não considera ocupação ou profissão é marginalizado socialmente. Essa segregação social do ponto de vista da saúde - com o respaldo de outras áreas do conhecimento como, por exemplo, a sociologia, a antropologia e a psicologia, dentre outras, uma vez que o conhecimento em saúde é constructo teórico/prático que se articula com outros saberes para entender e intervir criticamente na totalidade social - acarreta sérias implicações, como uma grande parcela da população brasileira composta por desempregados, subempregados instáveis, ambulantes, biscateiros, que dentro dessa lógica discriminatória não é considerada integrada ao sistema produtivo e, portanto, privada dos direitos de cidadania. Isso no tocante à saúde se traduz por falta de acesso à assistência sanitária suficiente e adequada, condições precárias, indignas e/ou insalubres de moradia, falta de acesso aos transportes coletivos adequados, salários baixos, falta de condições de alimentação com regularidade e teor nutritivo adequados, insegurança, violência, estresse e acentuada incidência e prevalência de doenças mentais.

Joel Birman (1988), na conferência “Abordagem Política dos Aspectos da Psiquiatria no Brasil" (Natal-RN, 1988), destacou a doença mental como motivo do maior número de mutilados socialmente no Brasil. Isto não por ausência de políticas de saúde, mas, sim, pela existência de políticas de exclusão em que, por excesso de jornada de trabalho, condições insalubres, baixos salários, péssimas condições de moradia e alimentação, e, ausência de lazer, os trabalhadores chegam à loucura ou procuram-na como recurso para se encostarem no INPS e assim ajudar na manutenção econômica da família. 
Essa constatação pode ser corroborada pelo depoimento de um paciente da Unidade Integrada de Saúde Mental de Mossoró-RN, que presta assistência ambulatorial em saúde mental a Mossoró e Região Oeste do Rio Grande do Norte. Por ocasião da interação de uma das autoras com grupos de espera para atendimento ambulatorial de acompanhamento psiquiátrico, um usuário declarou que tinha se "acostado no INPS”, o que ele assim justificava: No Brasil para se sobreviver, o trabalhador, como nós, se faz até de doido.

Cohn (1996) refere-se a esse aspecto da cai$x a$ sem fundo de paradoxos em que se constituiu a Previdência brasileira, destacando-se ainda:

(...) suspeição que recai sobre o beneficiário de sempre buscar benefícios previdenciários por meio da simulação. Exemplos não faltam: são freqüentes e recorrentes as suspeitas de que o trabalhador simula doenças para "encostar na Caixa" (receber benefícios por doença) (Cohn, 1996).

A política do desemprego segundo Reginaldo Morais apud Scherer (1988), deixa de fora 15 milhões de trabalhadores sem registro; $5 \mathrm{mi}$ lhões de subempregados; trabalhadores por conta própria com rendimento inferior a 1 salário mínimo; todos os trabalhadores rurais, mesmo com emprego fixo, por não serem contribuintes da previdência.

No que tange ao acesso à assistência de saúde, com a implantação do Sistema Único de Saúde (SUS), teoricamente, qualquer pessoa é igual e tem direito ao atendimento gratuito na rede estatal de saúde, quer seja do campo ou da cidade, não sendo necessária apresentação da Carteira da Previdência. Todavia, a garantia de acesso à assistência de saúde qualificada ainda é um sonho distante. Concorre para o desafio da implementação real do SUS o processo de sucateamento por que passaram e continuam passando os serviços públicos de saúde, onde o espaço físico é precário e/ou deteriorado, há falta de materiais permanentes e equipamentos técnicos, há falta de material de consumo diário, e má remuneração dos recursos humanos. Há ainda questões locais, como o próprio acréscimo da demanda. Se por um lado as possibilidades de acesso, de alguma forma, ampliaram-se, por outro lado, esbarram no limite da concretização desse acesso dos serviços públicos para atender de forma adequada a essa demanda, assim como o fechamento literal das portas dos hospitais e equivalentes conveniados pelo Inamps, alegando falência.

\section{Cidadania versus saúde mental no Brasil}

O cotidiano nas instituições que adotam implícita ou explicitamente a estrutura manicomial como modelo de assistência é conhecido, particularmente, por todos os profissionais que lidam com a área psiquiátrica e, notoriamente, pela sociedade em geral.

Além de uma realidade que causa indignação desde as primeiras e mais superficiais aproximações, é ainda, em sua grande maioria, um quadro aviltante à dignidade humana.

Moffatt (1984) fala do brutal empobrecimento desses lugares, como é o caso do pátio que deveria ser local de lazer - do hospício de mulheres de Buenos Aires, denominado pelo autor como pátio curral. Esse autor ressalta que não pretende negar a existência da loucura: ela existe e às vezes vai além do que se pode imaginar. Mas, em geral, o tratamento dispensado ao doente mental após a ocorrência do surto psicótico é uma espécie de readaptação ao convencional. Porém essa readaptação não é tão simples, porque a pessoa teve "cortados os seus viveres”, ou seja, seus vínculos com o mundo convencional, como por exemplo, chegam a ser despedidos dos empregos ou são rejeitados pela família e/ou comunidade. Configura-se assim, o que em psiquiatria denomina-se o estigma do paciente psiquiátrico, em que a maior amputação se constata na desqualificação, coisificação e conseqüente retorno ao ambiente manicomial, gerando a cronificação da vivência da doença mental.

O estigma de ser ou ter sido um paciente psiquiátrico tem desdobramentos que podem ser analisados sob vários matizes. Antes de tudo, podem remeter a uma discussão sobre as projeções da sociedade acerca da loucura. Estas projeções não se dão de forma gratuita, mas obedecendo à lógica do paradigma racionalista que engendra o modelo da normalidade das sociedades modernas hegemonicamente capitalista. Ainda sob tais projeções subtrai-se dos "anormais" a condição de cidadania, prerrogativa dos "ajustados".

Para Moffatt (1984), os pressupostos teóricos dos esquemas conceituais da psiquiatria tradicional estão baseados em preconceitos ideológicos muito mais que em comprovações científicas. Isto ocorre, na medida em que a psiquiatria como ideologia encontra-se vinculada ao modelo adaptativo-progressivo preconizado pelos grupos dominantes da sociedade. 
No que tange à cidadania, a presente exposição deixa vislumbrar por trás da constatação da amputação da dignidade humana, perda progressiva da auto-estima e da autonomia individual e coletiva, a conseqüência central do alijamento dos direitos de cidadania dos doentes mentais.

O direito de cidadania do doente mental deve ser o direito de receber assistência adequada, a garantia de participar da sociedade e de não ser pura e simplesmente jogado em depósitos, como ainda é uma realidade brasileira, na sua forma mais brutal, nos grandes hospícios públicos ou, nas formas mais sutis, em clínicas privadas e conveniadas.

O processo de discussão e iniciativas concretas no sentido de mudar a consciência coletiva e gerir a problemática do doente mental dentro da sociedade brasileira vem tendo um percurso longo e polêmico. O projeto de lei 3.657-A (1989) do deputado federal Paulo Delgado (PTMG), aprovado no Senado em janeiro de 1999 - após 10 anos de trâmite -, foi, enfim, aprovado na Câmara em abril de 2001. Este projeto é fruto do esforço de todo um movimento que, embora tenha seus avanços e retrocessos, suas contradições e descontinuidades, consegue neste momento atual consubstanciar-se como proposta concreta e viável a um futuro próximo de resgate da cidadania do doente mental no Brasil.

Considerando o contexto social brasileiro, os passos rumo a uma nova forma de pensar $\mathrm{e}$ lidar com o processo de sofrimento psíquico no Brasil merecem ainda amplo debate, discussões e divulgações em prol da participação dos envolvidos e da sociedade em suas instâncias democráticas, para que apenas não seja implantado o novo, mas que seja passível de acompanhamento e gerência pela população.

O movimento de Reforma Psiquiátrica brasileira vem encampando propostas de desinstitucionalização reforçadas pela Luta Antimanicomial. Este projeto de mudança representado no nível federal pelo projeto de lei supracitado, e em alguns Estados da federação por projetos similares - como, por exemplo, no Rio Grande do Sul, em 1992; no Ceará, em 1993; em Pernambuco, em 1994; no Rio Grande do Norte, em 1995; em Minas Gerais, em 1995 e no Paraná, em 1995 - é o resultado de um dos mais importantes processos de mudanças culturais para a sociedade brasileira nesse final de século, que diz respeito a uma revisão dos aparatos científicos, administrativos, jurídicos e éticos, relacionados com a doença mental.
Oliveira (1992) argumenta que as mudanças propostas pela Reforma Psiquiátrica brasileira refletem sobre três aspectos da vida social que são a organização social e suas práticas excludentes, a estrutura corporativista da medicina mental e os interesses do mercado. No primeiro, a desinstitucionalização coloca em risco a organização social brasileira ancorada em práticas excludentes e tutelares em relação aos loucos no paradigma da razão, do trabalho, da eficiência e da lei. Dentro desse primeiro aspecto, vale ressaltar que esta proposta abre precedentes para a possibilidade de construção/resgate da cidadania desta parcela da população, que esteve por muito tempo alijada de seus direitos, ou os teve manipulados por políticas e personagens sociais que agem à revelia dos discursos preconizados.

O segundo aspecto que é levantado pela proposta de desinstitucionalização e da luta antimanicomial refere-se à prática profissional dos trabalhadores que lidam com a área de saúde mental: A mudança de paradigmas gera uma outra crise, da estrutura corporativista (Oliveira, 1992). Para esta autora, a burocratização das práticas profissionais em saúde mental gera, além da cronificação dos doentes mentais, também a cronificação dos profissionais de saúde mental, devido à "neurose institucional", que causa nos trabalhadores desta área comportamentos e sentimentos de submissão, indiferença, ausência de projetos pessoais e futuros, apatia e deterioração dos vínculos. A proposta de mudança para este aspecto está na mudança da organização do trabalho de competências (especialistas e técnicos) para o conceito de equipe com um novo conceito de "profissionalidade" fundamentado na transdisciplinaridade do conhecimento.

Com este segundo aspecto dentro da lógica das mudanças, têm-se também algumas mudanças de qualidade na possibilidade de garantia da cidadania do doente mental: a desburocratização pode evitar a verticalização e as normatizações, muitas vezes autoritárias, da vida dentro das instâncias de tratamento de saúde mental; também amplia as possibilidades de uma prática mais criativa dentro das equipes de profissionais de saúde mental, mudando as relações de poder entre a equipe, a sociedade em geral, os doentes mentais e as instâncias governamentais.

O terceiro aspecto da quebra do paradigma institucional/manicomial vai repercutir na base econômica de um dos setores mais fortes dentro da sociedade brasileira (considerando, sobretudo, a sua ligação com o capital internacional), que é a indústria da saúde no Brasil, na sua 
versão particular da indústria da loucura, emblema do crescimento do número de internações psiquiátricas. Dentro desse terceiro aspecto, a questão da cidadania do doente mental remete não apenas à questão da cidadania mais geral do cidadão brasileiro em relação ao direito da saúde - como dever do Estado, exigindo deste que garanta uma assistência de qualidade gratuita e não privilegie as empresas privadas -, mas também a soberania brasileira em relação à divisão internacional do trabalho e particularmente da tecnologia no setor de equipamentos industriais/hospitalares e psicofármacos.

\section{Considerações finais}

Retomando o princípio de entrelaçamento intrínseco entre a luta pela cidadania em uma sociedade e o melhoramento dos serviços de saúde e da assistência prestada, podemos citar como divisor de águas no tocante às conquistas brasileiras o movimento pela Reforma Sanitária na saúde em geral, e a Reforma Psiquiátrica, os dispositivos legais de superação do manicômio e o Movimento de Luta Antimanicomial na saúde mental.

Segundo dados do Ministério da Saúde, é palpável a magnitude epidemiológica dos transtornos mentais, cuja prevalência em cidades brasileiras oscila de $20 \%$ a $50 \%$. Mundialmente, das dez doenças incapacitantes e que maior sobrecarga causam na vida das pessoas, 5 são de natureza psiquiátrica (Brasil, 1999).

O custo econômico de enfrentamento dessa problemática pelo sistema de saúde vale $\mathrm{R} \$ 700,00$ por mês, por paciente internado em hospital especializado, enquanto no centro/núcleo de atenção psicossocial equivale a $\mathrm{R} \$ 280,00$ mensais por paciente. Isso além das conseqüências advindas do modelo de atenção dispensado, que pode ou não priorizar fatores relevantes como acolhimento, vínculo e responsabilidade, historicamente negligenciados pelo modelo manicomial. Embora se comprove uma maior adequação da assistência ambulatorial dos Caps/ Naps para a melhoria dos serviços e aproveitamento positivo dos envolvidos, o Brasil possui, na realidade, 256 hospitais psiquiátricos e 232 Caps/Naps credenciados, onde o SUS emprega 95\% (432 milhões de reais) de seus investimentos financeiros para os serviços hospitalares e apenas 5\% (21 milhões de reais) para os procedimentos ambulatoriais do tipo Caps/Naps (Brasil, 1999).
O que o Ministério da Saúde está fazendo para mudar? Conforme as políticas de saúde mental do governo, além do apoio ao Projeto de Lei de Saúde Mental, o MS traçou três campos estratégicos de atuação, a saber: 1) com relação ao modelo assistencial: garantia do atendimento fármaco-clínico com extensão ou reconfiguração do modelo de atenção, em prol do incentivo ao Programa de Reabilitação Assistida (PRA); 2) no que tange à capacitação de recursos humanos e materiais para a reestruturação do cuidado: constituição de comitês e comissões de assessorias técnico-científicas, qualificação dos serviços e supervisão dos planos de saúde, assim como articulação com a Organização Pan-Americana de Saúde (Opas) e a Organização Mundial de Saúde (OMS) para o fortalecimento e divulgação da reestruturação do modelo de assistência à saúde mental; 3) com relação à participação comunitária e descentralização de políticas: negociações e alianças com a instância legislativa e com organizações, associações e movimentos representativos dos intersetores da saúde mental, como, por exemplo, o Movimento de Luta Antimanicomial (que possui representação de familiares e usuários), a Associação Brasileira de Psiquiatria, os prestadores filantrópicos e privados, a indústria farmacêutica, dentre outros (Brasil, 1999).

Acreditamos que a contribuição ao imprescindível debate da cidadania e saúde/saúde mental passa pelo debate perene das políticas públicas destinadas à saúde pelo Ministério da Saúde, pelas disposições do Legislativo, e pela participação consultiva e deliberativa da população. Resta superar o "medo do novo", realizando uma análise concreta - e por isso a partir de dados do MS, mas, principalmente, segundo as necessidades da comunidade, porventura não contempladas por esses dados - que supere os custos/benefícios de modelos anacrônicos em prol de novos custos/benefícios, cuja tendência deve estar centrada em novas formas de priorização da melhoria do cuidado em saúde mental.

Acreditamos ainda que a priorização da melhoria do cuidado dispensado encontra uma contribuição imprescindível no ideário da Reforma Sanitária, que, conforme Cohn (1997), "consiste na proposta de um sistema de saúde único, fundamentalmente estatal, sendo o setor privado suplementar àquele, sob controle público, e descentralizado". Vale enfatizarmos aqui a importância desse ideário como possibilidade para a conquista da cidadania plena (e não regulada). 
O que se busca, com a descentralização, é não só maior racionalidade do sistema de saúde, mas, fundamentalmente, a valorização da criação de novos espaços institucionais de participação, com poder deliberativo dos segmentos organizados da sociedade, constituindo-se assim como uma estratégia de ampliar, no espectro social, as oportunidades de acesso ao poder (Cohn, 1997).

No que tange à universalidade, à equidade $\mathrm{e}$ à descentralização da saúde no Brasil, encontramo-nos com o desafio do revertimento da lógica econômica que a vem caracterizando, através de uma reformulação radical na base de financiamento do sistema de seguridade social vigente, assim como o revertimento da lógica de financiamento da produção dos serviços privados de saúde prestados à população e, principalmente, o revertimento da lógica de financiamento na relação do setor público com o próprio setor público (Cohn, 1997).

Reverter potencializando, ou seja, considerando dialeticamente as possibilidades e os limites desse agir em saúde, pois se um dos principais obstáculos ao processo de descentralização como fator favorável à democratização política e

\section{Referências bibliográficas}

Amarante P (coord.) 1998. Loucos pela vida: a trajetória da Reforma Psiquiátrica no Brasil. 2a ed. Fiocruz, Rio de Janeiro.

Arendt H 1999. A condição humana. 9ạ ed. Forense Universitária, Rio de Janeiro.

Birman J 1988. VI Jornada de Psiquiatria do Rio Grande do Norte. Natal, out.

Brasil Ministério da Saúde 1999. Por uma política de saúde mental. Agosto.

Cohn A \& Elias PE 1996. Saúde no Brasil: políticas e organização de serviços. Cortez, São Paulo.

Cohn A 1997. Mudanças econômicas e políticas de saúde no Brasil. In Laurell AC (org.) Estado e políticas sociais no neoliberalismo. 2a ed. Cortez, São Paulo.

Costa MD 1988. A cidadania dos trabalhadores informais: uma questão de política pública. Serviço Social e Sociedade. Cortez, São Paulo, n. 26.

Costa NR 1986. Lutas urbanas e controle sanitário: origens das políticas de saúde no Brasil. Vozes-Abrasco, Petrópolis-Rio de Janeiro.

Covre MLM 1991. O que é cidadania. Brasiliense, São Paulo.

Dallari DA apud Scherer EF 1987. Classes populares e ampliação da cidadania. Serviço Social e Sociedade. Cortez, São Paulo, n. 23.

Fiori JL \& Kornis GEM 1994. Além da queda: economia e política numa década enviesada. In Guimarães R \& social vem sendo sua forma de financiamento, dados os critérios de repasse de recursos para os níveis locais, não resta dúvida que o nível local favorece a construção da democracia e o aprendizado do exercício da cidadania, na medida em que aproxima governo e sociedade. Assim como, em uma outra dimensão, as diferentes experiências de descentralização da saúde vêm revelando o nível local como espaço privilegiado de construção de identidades de novos sujeitos sociais como portadores de direitos. E isso remete não só à necessidade de se contemplar as diferenças na busca da eqüidade, mas significa também diversificar as possibilidades de campos de exercício da cidadania e de poder (Cohn, 1997), o que se reflete na saúde generalizada e se aplica similarmente à saúde mental em particular.

Para contribuição ao debate, reiteramos a articulação do setor saúde/saúde mental e cidadania no Brasil, situando as Reformas Sanitária e Psiquiátrica e, principalmente, o financiamento dos serviços advindos como fulcro das novas formas de atendimento e prestação de serviços perante as novas formas de exclusão social que vivenciamos nesse limiar do terceiro milênio.

Tavares R (orgs.) 1994. Saúde e sociedade no Brasil: anos 80. Relume-Dumará, Rio de Janeiro.

Fleury ST (org.) 1989. Reforma sanitária: em busca de uma teoria. Cortez-Abrasco, São Paulo-Rio de Janeiro.

Jaguaribe H apud Scherer EF 1987. Classes populares e ampliação da cidadania. Serviço Social e Sociedade, Cortez, São Paulo, n. 23.

Marshall TH 1967. Cidadania, classe social e status. Zahar, São Paulo.

Moffatt A 1984. Psicoterapia do oprimido: ideologia e técnica da psiquiatria popular. 5a ed. Cortez, São Paulo.

Morais R. apud Scherer EF 1987. Classes populares e ampliação da cidadania. Serviço Social e Sociedade n. 23. Cortez, São Paulo.

Oliveira CS 1992. Jornal do Conselho Federal de Psicologia. n. 32. nov/dez.

Paoli MC. 1983. O índio e a cidadania. Brasiliense, São Paulo.

Santos WG 1979. Cidadania e justiça. Campus, Rio de Janeiro.

Scherer EF 1987. Classes populares e ampliação da cidadania. Serviço Social e Sociedade, Cortez, São Paulo, n. 23.

Sposati A, Falcão MC \& Fleury SMT 1995. Os direitos (dos desassistidos) sociais. 2 a ed. Cortez, São Paulo.

Artigo apresentado em 25/2/2002

Versão final apresentada em 15/6/2002

Aprovado em 2/7/2002 